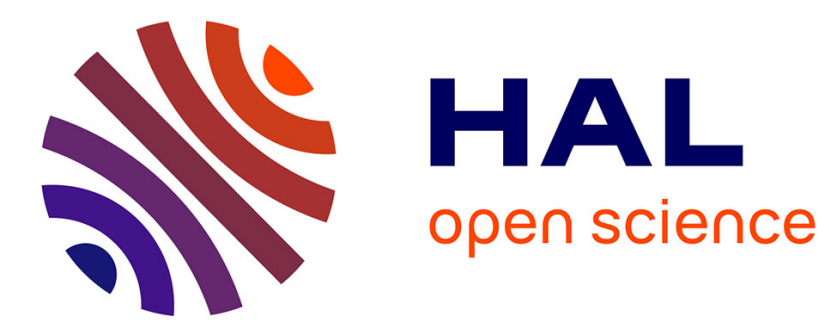

\title{
Complex nuclei in Oceanic languages: contribution to an areal typology.
}

\author{
Isabelle Bril
}

\section{To cite this version:}

Isabelle Bril. Complex nuclei in Oceanic languages: contribution to an areal typology.. I. Bril \& F. Ozanne-Rivierre. Complex predicates in Oceanic languages: Studies in the dynamics of binding and boundness, 29 (1), Mouton de Gruyter, pp.1-48, 2004, Empirical Approaches to Linguistic Typology. halshs-00006153

\section{HAL Id: halshs-00006153 \\ https://shs.hal.science/halshs-00006153}

Submitted on 24 Nov 2005

HAL is a multi-disciplinary open access archive for the deposit and dissemination of scientific research documents, whether they are published or not. The documents may come from teaching and research institutions in France or abroad, or from public or private research centers.
L'archive ouverte pluridisciplinaire HAL, est destinée au dépôt et à la diffusion de documents scientifiques de niveau recherche, publiés ou non, émanant des établissements d'enseignement et de recherche français ou étrangers, des laboratoires publics ou privés. 


\section{Complex nuclei in Oceanic languages: contribution to an areal typology ${ }^{1}$}

\section{Isabelle Bril}

Serial verbs and complex predicates have a long history of research that has produced an extensive literature (for an overview, see Senft this vol. and Sebba 1987). They have been described in various languages from different families and areas: Benue-Congo, Kwa languages of West-Africa (Lord 1993, Givón 1975), Atlantic creoles (Sebba 1987, Byrne 1991), Central America (Hale 1991), Northwest Amazonia (Aikhenvald 1999), various East and South-East Asian languages (Matisoff 1969, Bisang 1995, 1996), Australian languages (Evans 1985, Green 1995), Papuan languages (Bruce 1988, Foley 1985, 1997, Pawley 1993), some Melanesian Pidgins, and a number of Austronesian languages, more specifically those belonging to the Oceanic subgroup (Crowley 1987, Durie 1988, 1997, Early 1993, Bradshaw 1993, Crowley 2003).

Although Oceanic languages are generally not classified as heavily verb serializing, they present in fact a variety of situations ranging from productive (Paamese, Vanuatu, Crowley 1987: 35) to almost non-existent ${ }^{2}$. This diversity is reflected in the languages surveyed in this volume.

\section{An investigation into contiguous nuclei in Oceanic languages}

In contrast with previous research on serial verbs in Oceanic languages, which was mostly devoted to "core" serial constructions (i.e. noncontiguous nuclei $\operatorname{sV}(\mathrm{o}) \mathrm{sV}(\mathrm{o})$ ), this volume contributes a more detailed investigation of the "nuclear" type (i.e. contiguous nuclei $\operatorname{sVV}(0)$ ), which is the predominant and sometimes sole type exhibited by the languages considered.

Malcolm Ross has pointed out that, since about half of the languages analysed in the volume belong to the Papuan Tip and Polynesian subgroups of Oceanic languages, they may not be representative of Oceanic languages in general. In the Western Oceanic subgroup in particular, core layer serialization seems to be more common than nuclear layer serialization. 
In previous research, the "nuclear" type was often analysed as colexicalization, compounding or grammaticalization (Baker 1989: 521); but as Durie (1997) points out, such an exclusion probably rests on too restricted areal data. This volume provides new insights into this issue, new data for further typological research, as well as some structural and diachronic hypotheses which might account for the dominant "nuclear" pattern.

It has sometimes been claimed that "nuclear" serialization is correlated with verb-final order (SOV) and "core" serialization with verb-medial order; SVO languages are thus expected to display SVOV patterns ${ }^{3}$ (Baker 1989, Foley and Olson 1985: 45-47), while SVVO patterns in these languages are analysed as resulting from word order change or innovation (Crowley 1987: 78-79). However, most languages in this volume appear to combine basic verb-initial or verb-final pattern with a dominant nuclear type (see Table 3), thus contradicting these generalizations. They show the nuclear type to be compatible with all basic orders (VSO, VOS, SVO, SOV), with no evidence that this results from any word order change. Alternative explanations are offered in support of a more general evolutionary tendency towards structural compression, entailing the fusion of two or more nuclei and their argument structures. This, in turn, may lead to a further degree of fusion as lexicalized verb compounds, as grammaticalized entities or as Zaffixal morphemes.

\section{Definitions and criteria}

Verb serialization is defined by Bisang (1996: 533) as "the juxtaposition of two or more verbs, each of which would also be able to form a sentence of its own".

As "serial verbs" or "complex predicates" are broad cover terms representing a great variety of structural types, even among closely related languages, finer-grained definitions and criteria help restrict the phenomenon of verb serialization (Foley and Olson 1985, Crowley 1987, Durie 1997) both within the Oceanic Austronesian area and cross-linguistically. These criteria, summarized and discussed in Senft (this vol.) are as follows:

1) Verbs and Verb Phrases (or predicates or nuclei) constitute one single predication referring to aspects of a single event; ${ }^{4}$

2) These complex nuclei make up one clause, with no clause boundary or dependency marker; 
3) They constitute one single prosodic entity, without pause;

4) They share at least one syntactic argument or have a single array of arguments (for the specific case of "ambient serialization", see 2.1.1);

5) They share the same tense, aspect, mood (marked on $V_{1}$ or $V_{2}$ only or on all verbs), the same illocutionary force, the same affirmative or negative polarity, and the scope of negation bears on all nuclei;

6) No loss of stress pattern or phonological form (no syllabic reduction); no loss of morpho-syntactic or semantic properties of the nuclei;

7) Lexical autonomy is a prerequisite for serialization, excluding nonautonomous coverbs and nonfinite forms, as well as co-lexicalized compounds.

Complex predicates thus constitute one single grammatical unit. These criteria will be discussed in 2.3 below.

\subsection{Nuclear-layer and core-layer serial constructions}

In the Role and Reference Grammar approach adopted by many scholars working on Oceanic and Papuan languages, serial constructions are often described as being either of the core or of the nuclear type. These terms refer to the layered structure of the clause as defined by Foley and Van Valin (1984), Foley and Olson (1985), Van Valin and LaPolla (1997: 25).

\subsubsection{Definitions}

The "nucleus" or predicate has propositional function; these terms are used in avoidance of the notion of verb, which is not a universal category, as demonstrated by several authors (Foley \& Olson 1985: 33; Durie 1997) and as supported by data and analyses from Oceanic and more particularly from Polynesian languages in this volume. The "core" (or VP in languages with verbs) comprises the nucleus and its arguments. The periphery consists of the secondary participants (beneficiary, etc.) and adjuncts.

$$
\text { [ClAuse [CORE He [NuCL talked] to her] in the library] }
$$

Thus, nuclear serialization consists of several contiguous nuclei which share arguments, while core serialization consists of several cores. The core-layer subdivides into (a) same-subject and (b) switch-subject constructions (see Table 1). 
Table 1. Nuclear and core-layer serialization

\begin{tabular}{|c|c|}
\hline Nuclear-layer serialization & Core-layer serialization \\
\hline $\begin{array}{c}\mathbf{S V V ( o )} \\
{[\mathrm{I} \text { run catch (him) }]}\end{array}$ & $\begin{array}{l}\text { a) same-subject: } \mathbf{s V} \mathbf{~ s V}(\mathbf{o}) \\
{[\mathrm{I} \text { run I catch (him) }]} \\
\text { b) switch-subject: } \mathbf{s V o}(\mathbf{s}) \mathbf{V} \\
\quad(\mathrm{o}=\mathrm{s})[\mathrm{I} \text { strike } \underline{\underline{\text { im }}}(\underline{\mathrm{he}}) \text { dies }]\end{array}$ \\
\hline one single set of arguments & verbs share at least one inner argument \\
\hline
\end{tabular}

Crowley (1987: 40, 49) coined the term "ambient" serialization for a third type of core serialization in which the second core/ VP functions as a modifier of the first, with no argument-sharing, as in (1). 'Ambient' "refers to a term that makes a general predication about the world" (Chafe 1970: 101-102). Such constructions are found in Paamese (Vanuatu, Crowley 1987) and Tariana (Northwest Amazonia, Aikhenvald 1999: 481-82). In Paamese, argument-sharing is irrelevant and only bracketing morphemes and the scope of negation identify them as serial constructions.

Paamese, Crowley (1987: 71)

(1) Ki-pusi-e he-kaiho.

2SG.DIS-kick-3SG 3SG.DIS-be hard

'Kick it hard.' (lit. you kick, it is hard) (DIS = distant mood)

In Oceanic languages, both the nuclear and core types are common. But cross-linguistically, the core type, with its same-subject or switch-subject 'subtypes, seems to be the most widespread: the same-subject subtype generally expresses direction or sequential actions, while the switch-subject subtype Table 1 has causative, resultative or comitative functions and meanings.

\subsubsection{Overview of the various types in the languages of the volume}

In this volume, core-layer serialization is only attested in SOV Saliba and SVO Pileni (see Table 3). In Saliba, the core type is restricted to a few verbs with modal or aspectual semantics ('help', 'try', 'start') and marginally refers to sequential or purposive actions with co-ranking verbs; the nuclear type has modifying functions (specifying direction, manner of action, result, terminative aspect, see Table 7).

In Pileni, the core type often proves difficult to distinguish from multiclausal asyndetic constructions (coordination or purposive subordination), 
because of frequent pronoun gapping, ellipsis of TAM morphemes or dependency markers and lack of prosodic distinction.

\subsection{Symmetrical vs asymmetrical constructions}

Both the nuclear and core-layer types subdivide into two main structural "symmetrical" and "asymmetrical" subtypes, which mark different syntactic functions and relations (or "nexus", Foley \& Van Valin 1984).

The structural terms "symmetrical" (co-ranking) and "asymmetrical" (implying head-modifier hierarchy) will be used to avoid the syntactic terms "coordinate" and "subordinate".

Here, "symmetrical" does not refer to positions, since slots and linear order are generally constrained (see Saliba, Nêlêmwa), but to syntactically co-ranking predicates (i.e. on the same syntactic level) sharing the same subject; while "asymmetrical" predicates are hierarchized and headed and do not obligatorily share the same subject.

\subsubsection{Definitions}

- Symmetrical serial constructions consist of several co-ranking nuclei which belong to an open class, none of them determining either the semantic or the syntactic property of another verb of the sequence, and all under equal scope of a negation marker (Aikhenvald 1999: 472). They are time-iconic, refer to sequential actions which constitute one event or the various phases of a single event; they may also refer to concomitant actions (see Table 7). The "same-subject" core-layer type displays recursive copies of the same TAM and person markers on all verbs, a proof of their co-ranking structure. In other theoretical approaches, they are sometimes called "coordinate" or "pseudo-coordinate" (Baker, 1989: 524).

- Asymmetrical constructions (also labelled "subordinate" or "pseudosubordinate" constructions in other theoretical frameworks) comprise hierarchized nuclei (i.e. a head and a modifier). The head belongs to an open class, while the modifier may come from a smaller, closed class with a variety of meanings and functions (such as verbs expressing direction, motion, posture, property, cause-effect, aspect, modality, etc.). As Larson (1991: 199-200) points out, modification may just consist of a semantic (aspectual or modal) delimitation of the main action. The $\mathrm{V}_{1}$ or $\mathrm{V}_{2}$ in 
asymmetrical constructions tends to specialize and grammaticalize into an 'auxiliary-like' aspect or mood marker, or into complementizers.

\subsubsection{Overview of symmetrical and asymmetrical types in this volume}

Their distribution is highly variable across languages (see Table 2). For example, Nêlêmwa makes equal use of both types, while Mwotlap and Tahitian make sole use of the asymmetrical type. On the whole, in the languages of this volume, the asymmetrical type appears to be dominant with modifying functions, while the symmetrical type is restricted to a few constructions expressing sequential actions or goal of motion ('go and $\sim$ to + action'), as in Teop, Pileni and East Uvean; see Moyse-Faurie [ex. 10] olo si'aki 'go (and) leave...'.

Table 2. Asymmetrical and symmetrical nuclei or VPs.

\begin{tabular}{|c|c|c|c|c|c|c|c|c|c|}
\hline $\begin{array}{c}\text { Type of } \\
\text { construction }\end{array}$ & Saliba & Teop & $\begin{array}{c}\text { Mwot- } \\
\text { lap }\end{array}$ & Anejo & Nêlêmwa & Pileni & $\begin{array}{c}\text { East } \\
\text { Uvean }\end{array}$ & Samoan & Tahitian \\
\hline asymmetrical & $\begin{array}{c}+ \\
\text { nuclear }\end{array}$ & + & + & $*$ & + & + & + & + & + \\
\hline symmetrical & $\begin{array}{c}+ \\
\text { core }\end{array}$ & + & $*$ & rare & + & $(+)$ & rare & rare & $*$ \\
\hline
\end{tabular}

Among the languages which have either dominant or sole asymmetrical nuclear type, sequential actions are expressed by syndetic or asyndetic coordinated clauses (Mwotlap, Anejō̃, East Uvean, Tahitian, Samoan). In the asymmetrical nuclear type, the modifying nucleus is generally in the rightmost slot of the complex, irrespective of word order, SVO, VSO or VOS (Nêlêmwa) and even SOV (Saliba).

Among the semantics of modification, manner of action is common to all; the various other frequent meanings include direction, property, coincidence, result, terminative (see Table 7). As for the relation between adverbs and modifying nuclei, the situation is also variable: in Pileni, which lacks an adverb category, modification by contiguous nuclei fills a categorial gap; but this is not the case in the other languages in which modifying contiguous nuclei generally co-exist with adverbs, though for the expression of different semantic notions (as in Nêlêmwa, Mwotlap) or with adverbs derived by $v a$ - (Teop), $f a$ - (Samoan), faka- or by reduplication in East Uvean. 
Table 3. Types of complex predicates,

of word order and of argument structure.

Page 7, affix Table 3 (landscape)

see file "00 BRIL Tables 3 and 7"

年 


\subsection{Discussion of criteria}

Indispensable as they are, some of the criteria listed under Section 2 above are not sufficient to distinguish serial verbs, as we shall now see.

\subsubsection{Prosody}

The discriminating role of prosody is highly variable. In Anejo $\widetilde{m}$ and in the New Caledonian languages studied by Ozanne-Rivierre and Rivierre (this vol.), stress clearly differentiates sequential verbs from compounds, which constitute one single phonological unit, and in the tonal languages of New Caledonia (Cèmuhî, Paicî), the compounds take the tone of the prefix. In Nêlêmwa, prosody helps distinguish serial construction from asyndetic coordination. But in other languages (Teop, Pileni), prosody fails to be discriminating since a single prosodic contour serves for serial constructions and asyndetic multiclausal coordination or subordination.

\subsubsection{Shared TAM and polarity markers}

䄵The scope ${ }^{5}$ of negation and the sharing of TAM morphemes are often celusive criteria, except in languages with bracketing negative or TAM moriphemes (as in Mwotlap or Numbami):

Mwotlap (François) [ex. 49]

(2) Kêy $\langle e t-$ et VîGLAL te $\rangle$ no.

3PL $\mathrm{NEG}_{1}-$ see know $\mathrm{NEG}_{2} \quad 1 \mathrm{SG}$

'They did not recognize me.'

Numbami (Bradshaw 1993: 147; Oceanic, Morobe Province, Papua New Guinea)

(3) $\mathbf{M a}(\mathbf{n u})$ nu-kole nu-nggo ga de woya kote. DEHORT 2SG.IRR-turn 2SG.IRR-say talk to $1 \mathrm{SG}$ not

'Don't turn around and talk to me.' 


\subsubsection{Finiteness vs nonfiniteness}

Asymmetrical nuclei are cross-linguistically associated with nonfinite verb morphology; but as many Oceanic languages lack this distinctive feature or can dispense with redundant finite verb morphology, it is often difficult to distinguish the symmetrical and asymmetrical subtypes of contiguous predicates such as he runs (and) smiles and he runs smiling and many cases remain undecidable. Yet, in some languages, a few distinctive features help identify asymmetrical constructions.

- Some are morphophonological: the modifying verb has a slightly different form from an autonomous verb (Mwotlap, Nêlêmwa);

- some trigger a change of word order (Saliba, Teop, Pileni);

- others imply concord: transitive concord of $V_{2}$ with a transitive head ${ }^{6}$ (Saliba, Nêlêmwa, Pileni) or number concord with a plural first argument, marked by partial reduplication in East Uvean (for only about thirty intransitive verbs).

When no morphological clues are available, only semantics or the existence of closed classes helps assign the syntactic type and function of the complex predicate.

\subsubsection{Frequency and productivity}

Many Oceanic languages have various co-existing types of serial constructions, with different productivity, functions and properties (Durie 1997: 292).

Table 4 - Productivity of serial constructions.

\begin{tabular}{|l|c|c|c|c|c|c|c|c|c|}
\hline $\begin{array}{l}\text { Produc- } \\
\text { tivity }\end{array}$ & Saliba & Teop & $\begin{array}{c}\text { Mwot- } \\
\text { lap }\end{array}$ & Anejom & $\begin{array}{c}\text { Nêlêmwa } \\
\text { and North } \\
\text { N.C. lang. }\end{array}$ & $\begin{array}{c}\text { South } \\
\text { N.C. } \\
\text { lang. }\end{array}$ & Pileni & $\begin{array}{c}\text { East } \\
\text { Uvean }\end{array}$ & $\begin{array}{c}\text { Samoan, } \\
\text { Tahitian }\end{array}$ \\
\hline $\begin{array}{l}\text { of nuclear } \\
\text { or conti- } \\
\text { guous type }\end{array}$ & + & + & + & rare & + & $\begin{array}{c}\text { infre- } \\
\text { quent }\end{array}$ & + & $\begin{array}{c}\text { infre- } \\
\text { quent }\end{array}$ & + \\
\hline $\begin{array}{l}\text { of core } \\
\text { type }\end{array}$ & $\begin{array}{c}\text { infre- } \\
\text { quent }\end{array}$ & $*$ & rare & $*$ & $*$ & $*$ & $\begin{array}{l}\text { infre- } \\
\text { quent }\end{array}$ & $*$ & $*$ \\
\hline $\begin{array}{l}\text { of clause- } \\
\text { chaining }\end{array}$ & $*$ & $*$ & $*$ & $\begin{array}{c}\text { Echo- } \\
\text { Subject } \\
\text { Constr. }\end{array}$ & $*$ & $*$ & $*$ & $*$ & $*$ \\
\hline
\end{tabular}


Limited productivity is an evolutionary clue, signalling innovations or receding constructions. Three languages in this volume (Saliba, Teop, Pileni) evidence non-productive core-layer constructions, restricted to a few verbs.

In the North and Central Vanuatu subgroups, the various types are variably represented: in Mwotlap, the asymmetrical nuclear type is dominant and the core-layer type is infrequent and mostly expresses action-purpose, as in 'give me some water [so that] I drink' (François, this vol., fn. 7); in Araki', the core-layer type is pervasive (François, 2002: 189-200); in Lewo (SVO, Early 1993: 65-67), Paamese (Svo, Crowley 1987: 68, 78-9) and Namakir (Sperlich 1993: 108-9), the core type is dominant and the nuclear type involves either non-autonomous $\mathrm{V}_{2} \mathrm{~s}$, as in Paamese, or evolves towards verb incorporation with highly morphologized $\mathrm{V}_{2}$ which constitute a class of verbal suffixes, as in Lewo.

In the Southern Vanuatu subgroup, serial constructions are infrequent. In Anejom (Lynch, this vol.), this correlates with two factors: (i) the development of a dominant "echo-subject" clause-chaining construction for sequential actions (Lynch, Section 3), marked by a former coordinator grammaticalized as a proclitic "echo-subject" morpheme, in place of symmetrical serial verbs and (ii) in place of the asymmetrical/modifying -subtype, the development of verb compounds from former serial verbs, in Zwhich the second item has preserved many of its modifying functions (Lynch, Section 6).

In the languages of New Caledonia, serial verbs also vary from produc-tive (as in Nêlêmwa) to infrequent, as in some southern languages which have developed verb compounding and incorporation (Ozanne-Rivierre \& Rivierre, this vol.).

Among Polynesian languages, except in Samoan and Pileni, "juxtaposed" complex nuclei are not very productive; in East Uvean, they mostly express modification and only modification in Tahitian and Samoan.

\section{Types of nuclei, ordering principles and structural slots}

Though most of these features (types of nuclei, slots, ordering) are language-specific, yet there are widely distributed tendencies. 


\subsection{Types of nuclei}

Foley and Olson (1985: 41-43) have proposed a cross-linguistic hierarchy of verb types occurring in serial or complex verb constructions, with active intransitive verbs (of motion, direction, stance, posture) at the top and transitive verbs at the lowest point on the cline of frequency ${ }^{8}$.

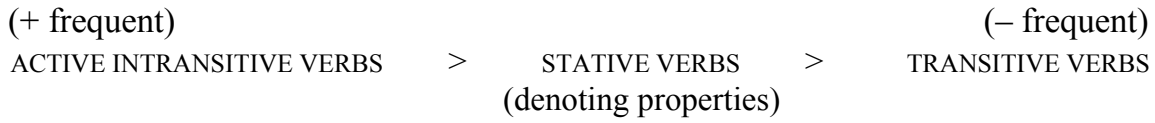

In Paamese (Oceanic, Crowley 1987: 50, 69), intransitive (motion or posture) verbs and stative verbs are common in core serialization, whereas other intransitive and transitive verbs are common in nuclear serialization. Most languages in this volume verify this hierarchy, though their distribution is highly variable.

The hierarchy also correlates with the core or nuclear types and their symmetrical or asymmetrical subtypes. For example, in Nêlêmwa, which only has nuclear serialization, stative verbs only appear in the asymmetrical subtype, while active intransitive or transitive verbs appear in both subtypes, though more frequently in the symmetrical one.

\subsection{Ordering principles: iconic ordering $v s$ parametric settings and} syntactic constraints

Is the ordering of nuclei in complex constructions constrained by a language's parametric settings and basic constituent order (head-first or head-last parameter, head-adjunct order) or rather is it conceptually and temporally iconic, based on the logical ordering of cause-effect, actionresult, action-goal semantics or inchoative and terminative Aktionsart?

\subsubsection{Ordering of complex predicates in sequential and modifying constructions}

One would expect ordering to be iconic for symmetrical complexes referring to sequential actions, but subject to the general order of modification in asymmetrical constructions. How does this interact with the basic constituent order, particularly in SOV Saliba? 


\section{Ordering in the VO and OV types}

In vo languages with head-modifier order, both sequential and modifying serial verbs merge into a unique frame TAM $\left[(\mathrm{S}) \mathrm{V}_{1} \mathrm{~V}_{2}(\mathrm{O})\right]$, in which $\mathrm{V}_{2}$ can either be the next sequential action or the modifier of $V_{1}$. The interpretation is either contextual or based on the types of nuclei and restricted slots which are specific to the modifying serialization.

Saliba (Margetts, this vol.) has mixed ordering features ${ }^{9}$, probably due to contact with OV Papuan languages. Thus in nuclear constructions, instead of the expected [modifier $\mathrm{V}$ main $\mathrm{V}$ ] order of OV languages, the modifying $\mathrm{V}_{2}$ is to the right of the main verb $\left[\mathrm{V}_{\text {main }} \mathrm{V}_{\text {modifier }}\right]$, as are adverbs. In OV Saliba, the ordered slots are as follows: [head-result-direction-adverbial or aspectual]. Terminative Aktionsart is iconic (action-finish). In purposive core serialization, action and goal of action are iconically ordered: the intransitive motion verb is in $\mathrm{V}_{1}$ position and the goal in $\mathrm{V}_{2}$ position; if transitive, $\mathrm{V}_{2}$ is preceded by its patient $\left[\mathrm{sV}_{\text {intr. }} \mathrm{OsV}_{\text {tr. }}(\mathrm{o})\right]$ as in [ex. 26] 'lit. $<$ they go yam they plant them > 'they go (and) plant yams'. This suggests that these verbs or VPs are co-ranking, not subordinate. Complement clauses also follow the main clause, in contradiction with Greenberg's Universal 13 and $15^{10}$ by which in OV languages, the subordinate verb form is expected to precede the main verb $\left[\mathrm{VP}_{\text {sub }}\right.$. $\left.\mathrm{VP}_{\text {main }}\right]$ and the subordinate -clause (of volition, purpose) to precede the main clause. Yet, it has often Zbeen remarked that many SOV Papuan languages (Kalam, Pawley 1987; Haruai, Comrie 1995) evidence this general tendency for sequential actions rand cause-result or action-goal complex verb constructions to be time-iconic. Consider Haruai (Comrie 1995: 34) in which the sentence 'that man cut some bananas, brought them (and) ate a little' - literally expressed as $<$ man-that banana cut carry little eat-past:3sg $>-$ shows both the timeiconic ordering of actions and the [modifier-head] order of the quantifier.

Thus, serial verb constructions often contradict the parametric settings of a language (see Carstens 2000) and favour time-iconic sequencing of serial verbs, whereas complement clauses are highly sensitive to the VO or OV parameters and could constitute a good distinctive criterion between both types. Durie (1997: 330-339) contends that the invariant sequencing of such serialized constructions proves the limits of the syntactic treatment of serialization and advocates a more cognitive or semantic approach. In support of this, Durie cites some language-specific semantic sequencing constraints: in Lahu, abstract verbs must precede concrete verbs (Matisoff 1969, in Durie 1997: 338); in Nêlêmwa (this vol.), the concrete verb always appears in $\mathrm{V}_{1}$ position and the abstract meaning of a verb often correlates 
with its modifying function in the $\mathrm{V}_{2}$ slot; thus, in the $\mathrm{V}_{2}$ slot, the verb $\hat{a}$ 'go, leave' may have the dispersive reading 'from place to place' and bwage 'go back, return' the reversive reading 'back'. Other languages specifically prefer verbs over directionals to express the abstract directions of verbs of perception or cognition.

\subsubsection{Ordering of inchoative, terminative and modal verbs}

If no other morphosyntactic clue is available, the iconic ordering of inchoative and terminative Aktionsart verbs is a possible indicator of serialization, in contrast with their grammaticalization as aspectual operators or with complementizing constructions (as in English start/stop doing something). In most of the languages of the volume, their position is iconic, even though they display various degrees of specialization, incipient deverbalization, morphological erosion and grammaticalization.

As for modality verbs ('try, able, hope, expect'), they tend to appear to the left of the main verb, while modifying verbs (of manner, result, direction) tend to appear to its right. Bi-directionality is thus common in asymmetrical constructions (see Bisang 1996: 580 for examples in Asian languages).

\subsubsection{Ordering of arguments and argument structure}

Argument ordering in serial constructions results from a compromise between (i) the constraints of a matrix verb's argument structure (i.e. the number and type of arguments it may subcategorize for), (ii) the constraints of a complex verb's argument structure and (iii) more generally the Thematic Hierarchy ${ }^{11}$. Durie (1997: 330-40) contra Baker (1989: 541, 544) contends that the ordering of verbs is basically iconic and cannot be reduced to the Thematic Hierarchy; on the contrary, the Thematic Hierarchy "is an artifact of verb sequencing constraints". Argument ordering in the languages of this volume involves composition, sharing and fusion; none of them allow for multiple objects or contiguous objects such as mentioned by Senft (this vol.) and Crowley (1987: 39, 50). 
3.2.3.1. Argument-sharing vs argument fusion in contiguous nuclear constructions

Argument-sharing is a powerful discriminating test for serial constructions (Foley and Olson 1985) though subject to much language-specific variation since neither subject nor object-sharing is universally obligatory.

\subsubsection{From compositionality to sharing and fusion}

a) In core-layer serialization, argument structure is compositional, each verb has its own arguments and the complex VPs are ordered according to language-internal parametric settings including constituent order and conceptually iconic order.

b) In contiguous nuclear constructions, argument structure ranges from shared arguments in symmetrical constructions to fused arguments in asymmetrical constructions. Foley and Olson (1985: 44) and more recently Durie (1997: 344-48) argue for argument fusion ${ }^{12}$ with "an integrated set of semantic roles" when two or more verbs differing in the argument structure of their lexical entries constitute a complex nucleus. The "fused thetahierarchy is not the simple addition of the theta-roles for the two verbs", it is a different conceptual structure altogether (Durie 1997: 348).

\begin{tabular}{|c|c|c|c|c|c|c|c|c|c|}
\hline & Saliba & Teop & $\begin{array}{c}\text { Mwot- } \\
\text { lap }\end{array}$ & Anejo $\widetilde{m}$ & $\begin{array}{l}\text { Nêlêmwa } \\
\text { \& North- } \\
\text { ern N.C. } \\
\text { languages }\end{array}$ & \begin{tabular}{|c|} 
Southern \\
N.C. \\
languages
\end{tabular} & Pileni & $\begin{array}{c}\text { East } \\
\text { Uvean }\end{array}$ & $\begin{array}{l}\text { Samoan } \\
\text { Tahitian }\end{array}$ \\
\hline $\begin{array}{l}\text { nuclear } \\
\text { or conti- } \\
\text { guous } \\
\text { type }\end{array}$ & SS & $\begin{array}{c}\text { SS } \\
\text { or DS }\end{array}$ & $\begin{array}{c}\text { SS } \\
\text { or DS }\end{array}$ & $\begin{array}{l}\text { infre- } \\
\text { quent }\end{array}$ & $\begin{array}{c}\text { SS } \\
\text { or DS }\end{array}$ & $(+)$ & SS & SS & SS \\
\hline core type & SS & * & * & $*$ & * & * & $\begin{array}{c}\text { SS } \\
\text { or DS }\end{array}$ & * & * \\
\hline
\end{tabular}

- In symmetrical constructions, subject-sharing is obligatory in all the languages of this volume; it is the primary criterion which distinguishes them from asymmetrical modifying constructions. Object-sharing only applies to transitive verbs which have the same patient $\left(\mathrm{SV}_{\text {tr. }} \mathrm{V}_{\text {tr. }} \mathrm{O}\right)$. If the sequence contains verbs with different valency, the intransitive verb (often a verb of motion) obligatorily precedes the transitive verb $\left(\mathrm{SV}_{\text {intr. }} \mathrm{V}_{\text {tr. }} \mathrm{O}\right)$, whether in Vo languages (Nêlêmwa, Pileni) or in OV Saliba $\left(\mathrm{SV}_{\text {intr. }} \mathrm{OSV}_{\text {tr. }}\right)$. 
- In asymmetrical constructions, there are two main cases. In Nêlêmwa, Pileni or Saliba, the complex verb has a single set of arguments which is based on the argument structure of the head $\left(\mathrm{V}_{1}\right)$, and the argument structure of the modifying verb $\left(\mathrm{V}_{2}\right)$, be it intransitive or stative, fuses with it. Thus a transitive $V_{1}$ will trigger transitive concord on $V_{2}$, which is marked by a transitive suffix $\left[\mathrm{SV}_{\text {tr. }} \mathrm{V}_{\text {trans }}{ }^{\text {ed }} \mathrm{O}\right]$ (as in Nêlêmwa, ex. (4) below or in Pileni) or an applicative affix as in Saliba $\left[(\mathrm{SO}) \mathrm{sV}_{\text {tr. }} \mathrm{V}(\mathrm{V})_{\text {appl.o]. The }}\right.$ inflectional concord in asymmetrical constructions is evidence that they constitute one complex predicative unit.

Nêlêmwa (Bril) [ex. 25b]
(4) Hia diya hâahuux-e mwa eli
3PL do be recent-TR house that.ANAPH
'They built this house recently.'

The second case is illustrated by Mwotlap, with only asymmetrical nuclear "macro-verbs" and strict SVO order: "in case of conflict for the object position [...] the macro-verb adopts the primary orientation of $\mathrm{V}_{1}$ and the secondary orientation of $\mathrm{V}_{2}$ " (François, 3.4. this vol.). Thus, in (5) two intransitive predicates make up one single complex transitive causative predicate with cause-effect or cause-result meaning within the SVO template and with a single argument structure.

\section{(5) Ne-len̄ 〈mi-yip hal-yak $\rangle$ na-kat. \\ ART-wind PFT-blow fly-away ART-cards}

'The wind blew the cards away.'

This is not a case of argument-sharing but of argument-restructuring and fusion, since in a non-serial construction, both verbs would be intransitive with different subjects.

A non-compositional argument structure (i.e. different from that of its constituent parts) for a complex verb often signals some functional specialization, grammaticalization or lexicalization. This is not quite the case in Mwotlap, but this might well be a transitional stage in a general process of compression from looser core serialization with different subjects (such as $<$ the wind blows the cards fly away $>$ ) towards compact nuclear transitive macro-verbs, in the process of specializing and grammaticalizing: $\mathrm{V}_{1}$ as a light causative verb or $\mathrm{V}_{2}$ as an adverb, according to the structural slot which attracts grammaticalization for a specific function. 


\subsubsection{Cross-linguistic comparisons}

Inflectional concord (in person, number) with the subject of the main verb or in transitivity with $\mathrm{V}_{1}$ signals one complex syntactic unit. In Tariana (Aikhenvald 1997: 476-78), causative serial constructions trigger subjectaffix agreement with the subject of the causation verb; this affix is cross-referenced on all verbs [you take you cause-cross you cause-stand].

Tariana (Aikhenvald 1997: 476-78)

(6) Phia-nikha phita pi-thaketa pi-eme you-REC.P.INFR 2SG+take 2SG-cross+CAUS 2SG-stand+CAUS

ha-ne-na hyapa-na-nuku

DEM-DISTAL-CL:VERT hill-CL:VERT-TOP.NON.A/S

ha-ne-riku-ma-se

DEM-DISTAL-CL:LOC-CL:PAIR-LOC

'Was it you who brought that mountain across (lit.you take you cross you put.upright) (the river) to the other side?'

(REC.P $=$ recent past, INFR $=$ inferred, $S=$ intransitive subject $)$

In Òbòlò (Niger-Congo, Faraclas 1984), subject-affix concord occurs in spite of switch-subject reading, but only in certain moods (positive imperative, hortative and subjunctive utterances) (7a.), and does not appear Fin the indicative (7b.), nor in the negative mood (Uche Aaron, in Durie 1997: 301). Durie, analyses such concord as a sign that they behave as co-heads and not as multi-headed VPs.

Òbòlò (Uche Aaron, cited in Durie 1997: 299, 301)

(7) a. É -gwên èmì $\boldsymbol{e}$-nûu

PL-call 1SG PL-come

'Let them call me to come.'

b. Èmì ń-sà ògè ífieĕk á-năm

I 1SG-use knife 3sG-cut meat

'I cut the meat with a knife.'

\section{Functions and semantics of serial constructions}

As Table 7 shows and as cross-linguistic studies confirm, contiguous serial or complex predicates are polyfunctional and polysemous constructions whose interpretation is filtered by various factors: the type of predicate or 
verb class, functional slots, types of collocations, as well as contextual inferences.

Among their common functions and semantics are sequential or coincident actions, modification (or value), specification of circumstances or manner of action, causative, resultative, purposive, aspectual and less frequently, case-role marking (benefactive, comitative). But the mapping between construction, functions and meanings is highly variable and not easily generalizable cross-linguistically.

\subsection{Distribution of types and functions}

The aforementioned functions may be mapped onto one to four different construction types (core or nuclear and their symmetrical or asymmetrical subtypes); yet few of the languages of the volume actually make use of them all. Some have three types (Saliba, Pileni), some two (Teop, Nêlêmwa), some only one (Mwotlap, Samoan, Tahitian).

To the asymmetrical subtype is generally assigned modification (property, value) or specification of circumstances (manner, result, location, etc.), while the less frequent symmetrical subtype expresses sequential or purposive actions (Teop, Nêlêmwa, Pileni).

Table 6. Serial constructions in Saliba and Pileni.

\begin{tabular}{|c|c|c|c|c|}
\cline { 2 - 5 } \multicolumn{1}{c|}{} & \multicolumn{2}{c|}{ nuclear } & \multicolumn{2}{c|}{ core } \\
\cline { 2 - 5 } & $\begin{array}{c}\text { asymmetrica } \\
1\end{array}$ & symmetrical & asymmetrical & symmetrical \\
\hline Saliba & $\begin{array}{c}\text { (mostly) } \\
\text { modification }\end{array}$ & $\begin{array}{c}\text { (infrequent) } \\
\text { Aktionsart, modal, } \\
\text { causative }\end{array}$ & $\begin{array}{c}\text { sequential, } \\
\text { purpose }\end{array}$ \\
\hline Pileni & modification & $\begin{array}{c}\text { sequential, } \\
\text { purpose }\end{array}$ & $\begin{array}{c}\text { (infrequent) } \\
\text { Aktionsart, } \\
\text { action-result }\end{array}$ & \\
\hline
\end{tabular}


Table 7. Typology of functions and meanings.

Page 18, affix first part of Table 7 (landscape) see file "00 BRIL Tables 3 and 7"

占 
Page 19, affix second part of Table 7 (landscape) see file "00 BRIL Tables 3 and 7"

先 
In Saliba and Pileni, the asymmetrical nuclear type has modifying function. In Saliba, the symmetrical core type, with co-ranking VPs, expresses sequential and purposive actions ('go to and sleep'), and the infrequent asymmetrical core type expresses Aktionsart, modal or weak causative meanings. In Pileni, the symmetrical nuclear type expresses sequential and purposive actions, and the infrequent core type expresses Aktionsart (incipient, terminative) and action-result. As Table 6 shows, sequential or purposive actions are more desententialized in Pileni than in Saliba, even though the symmetrical nuclear type in Pileni is unclear and might result from gapping or ellipsis.

At the other end of the cline, Mwotlap, Samoan and Tahitian use one single, highly polyfunctional pattern of asymmetrical contiguous nuclei (see Table 7) and sequential actions are expressed by multiclausal constructions.

In Saliba, Teop (Reinig [ex. 50]) and Mwotlap the causative, resultative or comitative functions and meanings, which are often expressed crosslinguistically by the switch-subject core-layer type $\left[\mathrm{S}_{1} \mathrm{~V} \mathrm{~S} \mathrm{~S}_{2} \mathrm{~V}\right]$ (as in $<\mathrm{S}_{1}$ makes $\mathrm{S}_{2}$ do something $>$ or $<\mathrm{S}_{1}$ hits sth. (as a result) $\mathrm{S}_{2}$ breaks $>$ or $<$ do sth. take s.o. $>$ ) are expressed by the compact $\mathrm{SV}_{1} \mathrm{~V}_{2} \mathrm{O}$ nuclear type, in which case the patient of $\mathrm{V}_{1}$ takes the next position available as the patient - of the macro-verb: in Saliba see Margetts [ex. 6] $<\mathrm{SV}_{\text {pull }} \mathrm{CAUS}-\mathrm{V}_{\text {straight- }}$

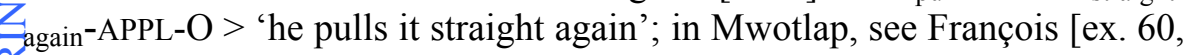
61] with têy 'hold' or [ex. 37] < make stay quiet him >.

年

4.2. Case-role marking and argument expansion

Argument expansion ${ }^{13}$ and case-marking are two of the common crosslinguistic functions of serial constructions. In several African languages, Akan, Yoruba and Ijo (Sebba 1987), serial constructions have been described as essentially an argument increasing strategy. Sebba (1987: 216) shows that all three languages have strict limitations on argument structure (also see Carstens 2002), and Ijo only allows two arguments per verb, just like Mwotlap (this vol.). Foley (1997) pointed out that Austronesian languages tend to avoid three argument verbs and use complex verbs for case-marking and argument-adding functions. If the gap-filling function certainly holds true for Nêlêmwa (this vol.), where a few verbs may have argument-adding and case-role marking functions which compensate for non-existent prepositions or morphological markers, yet, neither poor 
morphology nor the gap-filling function of serialization can be generalized further, even less held as universal features. Various Amazonian languages exhibit both very rich verbal morphology as well as serialization (Aikhenvald 1999). Bisang (1995: 138) makes a similar remark about Jabêm (Western Oceanic, Papua New Guinea). Haitian has three argument verbs as well as argument-expanding serial verbs (Déchaine 1989: 239). In Sranan and Saramaccan (Atlantic Creoles, Sebba 1987: 213-15), in some Amazonian languages, in Alamblak (Papuan, Bruce 1988), in Thai (Foley and Olson 1985), prepositions are shown to coexist with serial constructions, though with slightly different semantic and syntactic properties. In Alamblak (Bruce 1988: 37-38), serial causatives express indirect causation (lit. 'the wind blew me cold'), whereas the derived causatives express a more direct causation (such as 'he made her enter'). Thai (Foley and Olson 1985: 54) is also reported to have both an instrumental preposition dûay '(along) with, too' and a serial construction with the verb ?aw 'take' which highlights the instrument, in contrast with the prepositional instrument, which is out of focus.

The verbs used as argument expanders or case-role markers are known to grammaticalize into adpositional markers or coverbs (Bisang 1996: 521$24)$, but there is an intermediate stage during which these verbs still head verbal arguments rather than prepositional adjuncts.

\section{Which theoretical approach for serial constructions?}

There are ongoing debates as to whether serialization is relevant to syntax and phrase structure (dependency, chaining), to lexicon (compounds, lexical enriching), to reference-tracking (same $v s$ switch reference), to argument and case-role marking, to semantic and iconic temporal ordering (for sequential or coincident actions) or to several - or all - of these levels at the same time (Sebba 1987). Various theoretical approaches and models have been proposed, among which Sebba (1987), Baker (1989), Zwicky (1990), Byrne (1991), Givon (1991), Seuren (1991), Larson (1991), to mention but a few; but there is as yet no agreement on the syntactic model that might represent such a structural type, and, given the variety of configurations and linguistic types involved, Durie (1997) even voices strong doubts that there might be such a model. The only notion that generally meets agreement is that serial constructions make up one single complex 
predicate with shared arguments and constitute one complex event. The three main positions will briefly be presented.

\subsection{The syntactic vs the lexicalist approach}

Sebba (1987) and Baker (1989: 523, 545-50) analyse serialization in various SVO Creole and African languages as a syntactic process involving recursive categories based on the notion of tightly knit and multiple rightbranching verb phrases. Ordering is constrained both by the syntactic and structural parameters of a given language (such as the head-adjunct parameter) and by Thematic Hierarchy. The SVOV pattern is analysed as object-sharing with a VP as the dominating node:

"serializing languages allow Vs to embed within V' to form a doubleheaded construction $[\ldots]$ this creates the possibility and the obligation of two verbs theta-marking the same internal argument." (Baker 1989: 550).

In the lexicalist approach, serialization is analysed as taking place in the lexicon (Lefebvre 1991: 70); that is, matrix and serial verbs are considered either as (i) homophonous, different lexical items, (ii) or as forming a single complex predicate in the lexicon with a single argument structure 5 (resulting from the composition of each verb's argument structure) which theta-marks for a single set of arguments.

Durie (1997: 344-450) points out that a verb has a different lexical conceptual structure when serialized or not. Serialized verbs form a gram-matical unit, which may modify the semantic and morphosyntactic properties of each verb.

"The semantic contribution of arguments can only be understood in the context of the whole serial complex". [In instrumental take-hit constructions], "the first object is understood as an Instrument, by virtue of the interaction of the meanings of the two verbs' argument structure." (Durie 1997: $345)$.

5.2. Discussion: a cline between syntax, lexicon and conceptual structure

Foley (1986) and Pawley $(1987,1993)$ showed that languages vary greatly in the way they categorize event-types and complex notions, (i) either by 
one single verb, e.g. grab $^{14}$ or (ii) by co-lexicalized formulas ${ }^{15}$ such as 'hand raise go touch hold' (Foley 1986) or (iii) by several clauses.

Durie (1997: 326-27) observes that when serial constructions are cultural constructs, conventionalized concepts or formulas or when they have lexicon-expanding functions to make up for lexical verb scarcity as in Papuan ${ }^{16}$ languages (Bruce 1988, Pawley 1987, 1993; Lane and Pawley 1992), then syntax should not have much effect on theoretical explanations or models (see also Senft, this vol.). Besides,

"the productivity of verb serialization is constrained in such a way that a large variety of syntactically well-formed verb combinations will be rejected by native speakers as unacceptable or ungrammatical, because they do not correspond to a recognizable event-type, either within the actual experience of speakers, or alternatively within the permitted patterns of verb serialization within a language". (Durie 1997: 322).

In Kalam, Pawley and Lane show that these complex verb chains fall somewhere on a cline between serial verbs, lexical compounds or conventionalized formulas. These verb chains are submitted to judgement of acceptability and idiomaticity and specify phases or components of a unique complex "event", which Pawley (1987: 333; 1993: 109) defines as a subjective conceptual construction of a bounded happening (action or process) and a formal construct on which several functions and meanings are mapped. Pawley adds that if such verb chains involve lexical compounding, it is a productive lexical process which combines verbs into series without necessarily generating new dictionary entries for them.

In less extreme language types, nuclear serialization is often intermediate between syntactic and lexical phenomenon and can thus evolve towards grammaticalization or co-lexicalized compounds, in contrast with less desententialized core juncture. Early (1993: 81-85) also states that while "syntax rather than lexicon is the best place to handle the description of core serialization" in Lewo (Vanuatu), nuclear serialization is more highly desententialized because of the absence of TAM and person marker on each verb and may gradually fade into lexicalization and compounding. But languages vary greatly in this respect. Anejo $\widetilde{m}$ with its "echo-subject" chaining markers (Lynch, this vol.) and Paamese (Vanuatu, Crowley 1987) with its dominant core serialization are less advanced in this process of desententialization.

Since co-lexicalization and compounding are gradual, ongoing evolutionary processes observable in the synchronic grammar of a language, it may be difficult to draw a clear-cut line between the various stages that 
lead from serial verbs to incipient co-lexicalized predicates (see Nêlêmwa and Mwotlap, this vol.), except when they have reached an advanced degree of morphophonological fusion and when there is clear prosodic or tonal evidence that they constitute one stress or tonal unit (see Rivierre \& Ozanne-Rivierre this vol.). Reduced productivity, analysability, paraphrasability and reduced semantic predictability are additional criteria to identify lexicalization, compounding and grammaticalized verbs.

Durie (1997: 330) points out that the invariance of cause-effect, instrumental or goal serial verb sequencing in SVO and SOV languages makes it "implausible that serialization sequencing constraints can receive a general explanation through syntactic accounts alone". He suggests that "models of lexical conceptual structure and event-hood [...] will also need to be deployed to deal properly with verb serialization" in order to understand "which properties of serialization are manifestations or projections of semantic structure, culture-specific constructions of event-hood and tendencies of grammaticization and lexicalization." (ibid. 1997: 349). Senft (this vol.) stresses that serial constructions might be the manifestation of some cognitive process, favouring an analytic rather than a synthetic mode of categorization and expression.

\section{Complex predicates in a typology of dependency \\ م \\ Dependency can generally be defined (i) as operator dependency (entities qunder the scope of the same TAM, polarity and illocutionary operator(s)), (ii) as relations of dominance within hierarchical structures or (iii) as rela- tions of governance between constituents. This encompasses several types of constructions ranging from coordination to subordination. \\ Complex predicates may evidence dependency in all these senses as they are highly integrated constructions. TAM operator dependency is definitory of serial constructions; asymmetrical serialization displays addi- tional relations of dominance (head-modifier relations). But relations of governance (such as complementation) are normally excluded from serialization since they involve clause juncture (Seuren 1991: 196-203). Yet, there are ambiguous cases which may be interpreted either as symmetrical, co-ranking serial constructions or as governed nuclei or cores (i.e. arguments or complements of a governing predicate).}




\subsection{One or several clauses?}

If there is fairly general agreement that serial predicates constitute one clause, interpretations vary as to what the underlying structure and concatenation principles are: (i) asyndetic coordination, pseudo-coordination and paratactic sequences, (ii) more or less loose adjunct construction (adverbial type) (Muysken and Veenstra 1994; Veenstra 1996), (iii) asyndetic subordination, (iv) ungoverned pseudo-complementation ${ }^{17}$ (Zwicky 1990: 3; Seuren 1991: 196-97, 201), (v) governed pseudo-complementation ${ }^{18}$ as in he stopped writing.

Baker (1989: 514-15) also recognizes that while "some putative SVCs are instances of veiled coordinations, embedded clauses, prepositional phrases, adverbs or particles", some others, which he calls serial constructions, can be shown to be different on a number of criteria (such as extraction patterns, clefts, anaphors); besides, "true SVC structures and covert coordination structures seem to feel different to native speakers. The SVC is perceived as a single event" (Baker 1989: 546).

Serial constructions are monoclausal while complex predicates do not have such restrictions. Some types of complex predicates are reduced dependent clauses resulting from pronominal gapping or conjunction ellipsis. They can either be co-ranking verbs as in English go (and) get it, come (and) fetch it, or (+/-contiguous) asymmetrical verbs in weak causative constructions such as he helped (to) finish it or she helps me (to) do it, where $\mathrm{V}_{2}$ is a nonfinite secondary verb. In English, co-ranking verbs are restricted to a few verbs in imperative mood or base forms (she'll go get $i t$ ), but are ungrammatical with conjugated forms (*I went got the paper), consequently they are not serial verbs.

In Pileni and Teop (this vol.), gapping is the norm and with few morphological markers and syntactic tests available, the syntactic relation between units (i.e. the type of nexus) is elusive; nor are operator scope and prosody any more helpful. Thus, in Pileni, nuclear or core serial verbs are difficult to distinguish from asyndetic coordination or subordination. With such formal and prosodic indeterminacy, distinctions and labels vary from language to language or are a matter of theoretical approach, and the only general notion that holds is that serial and complex verb constructions constitute a tight linkage type which spans a wide domain of mono-clausal or interclausal relations and functions.

Foley and Van Valin (1984), Foley and Olson (1985), Van Valin and LaPolla (1997) analyse such phenomena with three levels of juncture 
(nuclear, core and clause), combining with three types of nexus (coordination, subordination, cosubordination) to generate nine possible complex sentence types on a cline from tight to loose integration into a single unit (Van Valin \& LaPolla 1997: 477). Because of the great variability of morphosyntactic types and constructions exhibited by complex constructions (serialization, participial and converbal forms, medial clauses, etc.) and because of the highly variable mapping of conceptual relations onto the syntactic structures which encode them and which do not always fall neatly into coordination and subordination patterns, the notion of a hierarchical cline of interclausal linkage (from autonomy to integration), correlated with a cline of tightness of linkage (from implicit to explicit, Lehmann 1988) and correlated with semantic integration, is a preferred option for many scholars (see Foley \& Van Valin 1984).

6.2. Symmetrical and asymmetrical nuclei: equal rank, dominance and governance

Serial constructions generally exist along with other modes and markers of dependency, such as tight or loose syndetic coordination, complementation or subordination.

\section{\%}

\subsubsection{Functions of symmetrical and asymmetrical nuclei}

In Nêlêmwa, symmetrical, co-ranking nuclei refer to sequential actions and may often be rephrased as multiclausal syndetic or asyndetic coordination, yet they cannot be reduced to elliptic or asyndetic coordination for there are clear prosodic, syntactic and semantic differences in terms of event-frame: asyndetic coordination involves a pause and refers to different clauses and distinct events, whereas co-ranking nuclei refer to time-iconic sequential actions or to coincident actions which constitute one clause and one complex event. 
Table 8. Types of constructions for sequential actions

\begin{tabular}{|c|c|c|c|c|c|}
\hline Saliba & $\begin{array}{c}\text { Teop / } \\
\text { Mwotlap }\end{array}$ & Anejom & $\begin{array}{c}\text { Nêlêmwa and } \\
\text { North. N.C. } \\
\text { languages }\end{array}$ & Pileni & $\begin{array}{c}\text { East Uvean / } \\
\text { Tahitian / } \\
\text { Samoan }\end{array}$ \\
\hline $\begin{array}{c}\text { core-layer } \\
\text { sequence } \\
\text { of VPs }\end{array}$ & $\begin{array}{c}\text { syndetic or } \\
\text { asyndetic } \\
\text { coordinated } \\
\text { clauses }\end{array}$ & $\begin{array}{c}\text { clause- } \\
\text { chaining, } \\
\text { multi- } \\
\text { clauses }\end{array}$ & $\begin{array}{c}\text { nuclear SVCs } \\
\text { or syndetic / } \\
\text { asyndetic } \\
\text { coordinated } \\
\text { clauses }\end{array}$ & $\begin{array}{c}\text { core-layer } \\
\text { sequence of VPs } \\
\text { or syndetic / } \\
\text { asyndetic } \\
\text { coordinated } \\
\text { clauses }\end{array}$ & $\begin{array}{c}\text { syndetic or } \\
\text { asyndetic } \\
\text { coordinated } \\
\text { clauses }\end{array}$ \\
\hline
\end{tabular}

Symmetrical or asymmetrical nuclei: some ambiguous cases

Contiguous nuclei often generate some syntactic and semantic ambiguity between co-ranking, sequential actions or asymmetrical predicates with adverbial or circumstantial meaning. In Nêlêmwa, the contiguous nuclei $i$ walem gi (lit. (s)he walk cry) may be interpreted either as symmetrical nuclei '(s)he walks and cries' or as asymmetrical nuclei similar to copredicative participles such as '(s)he walks crying'. Yet, $i$ walem gi constitutes one event and differs from two coordinated nuclei $i$ walem me gi 'he walks and cries' or two coordinated clauses $i$ walem me $i$ gi 'he walks and he cries', which refer to two events. In Pileni (Næss), contiguous nuclei such as [ex. 9] have the same ambiguous readings: co-ranking as in 'he paddled (and) searched' or asymmetrical and adverbial as in 'he paddled searching'; such ambiguity is increased by pervasive gapping and conjunction ellipsis. In East Uvean (Moyse-Faurie), contiguous nuclei such as [ex. 9] hopo malimali 'jump and smile' or 'jump smiling' are similarly ambiguous.

The main disambiguating criteria are mostly verb slots $\left(\mathrm{V}_{2}\right.$ is most often the modifier slot, even in SOV Saliba), verb classes, contextual inferences and semantic collocations.

On the whole, the Polynesian languages in this volume tend to restrict contiguous nuclei to modification and to resort to multi-clause constructions for sequential actions. But even with modifying function, East Uvean prefers "depredicativized" and "deserialized" constructions to contiguous nuclei (Moyse-Faurie, 1.3. [ex. 27 to 29]). In Tahitian (Paia \& Vernaudon), neither sequential nor coincident actions may be encoded by contiguous nuclei: 'he nibbles (while) reading' or 'he telephones (while) driving' require either deranked prepositional phrases (lit. he drives with the telephoning) or multiclausal syndetic or asyndetic coordination. Samoan 
(Mosel) also uses similar constructions as an alternative to complex nuclei, compare examples (50) and (51): [ex. 50] (lit. 'it does not grow high'; [ex. 51] lit. 'it is not high its growing'. In contrast with East Uvean and Tahitian, Samoan (Mosel) uses contiguous nuclei for coordination or additive properties (see [ex. 17] 'the leaf is black and thin') and more infrequently, for coincident actions, together with time iconic ordering of nuclei: see [ex. 11] 'she leaned crying and sobbing' (lit. cry sob lean), [ex. 21] 'the eel cried and spoke/spoke crying...' (lit. cry talk) and [ex. 23] 'sit praying'.

\subsubsection{Another type of dominance: clause-chaining and medial verbs}

Clause-chaining or "medial verb constructions" are defined by Longacre (1983: 186) as "a sequence of one fully finite verb and a number of less finite medial verbs", which must be under the scope of the same tense, mood and illocutionary operators as the main verb (sometimes eliminating them). Medial, dependent verb forms are marked by cliticized morphemes which are distinct from those used on simple main clause verbs, which eliminate agreement markings and are sometimes specified for same or different subjects. Clause-chaining has mainly been described among rightheaded (OV) Papuan languages ${ }^{19}$ (Comrie 1983: 30, Foley 1986, Roberts 1988, Farr 1993, Bradshaw 1999). It is infrequent in Oceanic languages I(Lynch et al. 2000: 48), but a similar phenomenon, "echo-subject constructions", is described in the South Vanuatu subgroup: Anejo $\widetilde{m}$ (Lynch, this vol.), Lenakel (Tanna island, Lynch 1983) and Sye (Erromango island, Crowley 1998). In Anejom (Lynch, Section 3, this vol.), contiguous verbs are very infrequent and the dominant pattern for sequential actions is a type of clause-chaining called "echo-subject construction" (ES) and marked by a cliticized former coordinator $(\mathrm{m}-)$. This proclitic requires the same subject (SS) constraint and replaces person-tense-mood morphemes. In Sye (Crowley 1998: 247), ES-marking is pervasive, it conflates the functions marked both by symmetrical and asymmetrical serial constructions, that is both sequential or coincident actions as well as asymmetrical modification (the ES verb may express manner of action, direction, comparison, Aktionsart 'finish').

Being operator-dependent, medial verbs constitute an intermediate type of linkage, labelled "cosubordination" (Foley \& Van Valin 1984) or "dependent" or "deranked" coordination (Roberts 1988, Lehmann 1989, 
Haspelmath 1995: 21-23, Croft 2001: 354-55), and though they "span the region between coordination and adverbial subordination" (Croft 2001: 322-23), they are more akin to coordinate than subordinate clauses. One source of same-subject affixes in clause-chaining happens to be grammaticalized coordinating conjunctions (Haiman 1983: 106, 1987; Mithun 1988).

\subsubsection{Governance: contiguous nuclei vs complementation}

Contiguous nuclei or complex predicates have a variety of functions which range from co-ranking coordinate-like to hierarchized subordinate-like functions. Croft (2001: 323-24), citing Noonan (1985: 78), mentions an ambiguous case of linkage in Lango (Nilo-Saharan), in which paratactic clauses such as $<$ I remembered I closed the door $>$ may also be interpreted as asyndetic complement clauses such as 'I remembered to close/closing the door'. Pronoun gapping, ellipted TAM markers may then yield two contiguous nuclei with shared arguments.

In Samoan [ex. 12 to 14], Mosel analyses contiguous nuclei involving 'begin', 'know', 'go' (as in 'go buy some sugar') as compressed, ellipted two-clause constructions.

Aktionsart and modal verbs often specialize as semi-auxiliary operators and undergo gradual delexicalization which then triggers clause compression:

" $[\ldots]$ the final stage of the grammaticalization of complements can be the fusion of the complement to a highly generalized main verb, indicating causation, mood or aspect." (Croft 2001: 351).

But there are intermediate stages in which contiguous nuclei involving Aktionsart and modal verbs such as 'try, help, start, know' are syntactically ambiguous between co-ranking serial verbs and cosubordinate or governing constructions with dependent nuclei (see Saliba, Teop, Nêlêmwa, Pileni and East Uvean).

In spite of the lack of finite vs nonfinite morphology, there are a number of language-specific tests that help clarify their status. Comparison with syndetic constructions with similar functions and meanings is a good test to assess the basic differences between serial verbs and asyndetic dependent clauses. In Nêlêmwa, governing verbs generally select specific types of complementation markers, except a few verbs such as 'start, know, try' (see Nêlêmwa, Bril, 2.10; 2.11) which are structurally ambiguous. As far as 
Aktionsart verbs are concerned, the iconic position of 'start' in $\mathrm{V}_{1}$ and 'finish' in $\mathrm{V}_{2}$ position is an argument in favour of their analysis as coranking or cosubordinate constructions, in contrast with the non-iconic position of similar verbs in other languages such as English he stops doing it (not to mention the nonfinite $\mathrm{V}_{2}$ ), which indicate complementation. The construction of 'start' in Nêlêmwa actually depends on the valency of $\mathrm{V}_{2}$ : it is cosubordinate with an intransitive $V_{2}$, but governing with a transitive $V_{2}$ (see Nêlêmwa, Bril, 2.10). As for 'finish', it fits into the modifier $\mathrm{V}_{2}$ slot and behaves as an aspectual modifier of $\mathrm{V}_{1}$.

In Saliba, the construction of 'help', 'start' and 'try' (Margetts, 6.4 to 6.6.) shows some evolution either (i) towards more compression, from core to nuclear juncture with shared arguments, or (ii) towards a deranked, converbal, nominalized verb form $\left[\mathrm{O}_{\text {cake }} \mathrm{V}_{\text {bake-Poss. }} \mathrm{sV}_{\text {try }}\right]$ (lit. cake bakingits I try) functioning as the complement of the main verb (see footnote 10). Thus, the core juncture [ex. 54] [O $\mathrm{O}_{\text {Lalaita }} \mathrm{SV}_{\text {help-APPL-3SG.O }} \mathrm{sV}_{\text {basket.weave }}$ ] 'help Lalaita to weave baskets' (lit. Lalaita you $\mathrm{sg}$ help her you weave) gives way to a single complex nuclear juncture [ex. 54'] [ $\mathrm{O}_{\text {Lalaita }} \mathrm{sV}_{\text {basket.weave }} \mathrm{V}_{\text {help-APPL.-3SG.O }}$ (lit. Lalaita you $\mathrm{u}_{\mathrm{sg}}$ basket weave help her) with an inverted word order to comply with Saliba's constrained syntactic slots in nuclear constructions, 'help' then appears in the modifying $\mathrm{V}_{2}$ slot. With 'start' and 'try', there is no order inversion Z(possibly due to iconic reasons), thus [ex. 46] [ $\mathrm{sV}_{\text {start }} \mathrm{O}_{\text {skirt }} \mathrm{sV}_{\text {weave }}$ (lit. I ?start skirt I weave) becomes [ex. 50a.] [ $\mathrm{O}_{\text {skirt }} \mathrm{sV}_{\text {start }} \mathrm{sV}_{\text {weave }}$ ] (lit. skirt I start I weave), by raising the object to the position of object of a core juncture, which might possibly develop into contiguous nuclei at a later stage ${ }^{2}\left[\mathrm{O}_{\text {skirt }} \mathrm{sV}_{\text {start }} \mathrm{V}_{\text {weave }}\right]$ (lit. skirt I start weave), as a consequence of subject pronoun gapping [(SO) sVVo].

\subsection{Asymmetrical complex nuclei and converbs: a comparison}

Asymmetrical complex predicates expressing the manner, coincidence or circumstances of an action (see 6.2.1 above) may be analysed as cases of cosubordination. They are encoded cross-linguistically by a wide range of syntactic constructions, morphological markers or lexical categories: nonfinite verb forms (infinitives, gerunds), co-predicative participles (I sat watching the scene, he arrived holding the lamp, French traverser la rivière en nageant), nominal modifiers (traverser la rivière à la nage), prepositional phrase (swim across the river), adverbs or adverbial forms, 
converbal affixes, preverbal or postverbal particles or affixes. Compare serial verbs and complex predicates such as $<$ lit. hit die $>$ and strike dead with German totschlagen or $<$ lit. pull come out $>$ with pull out and herausziehen, or $<$ lit. scratch remove $>$ with scrape away and wegschaben (Sebba 1987: 217; Rousseau 2000: 390-91).

Serial verbs such as Nêlêmwa thege ulep $d u$ (lit. run pass down) are akin to complex predicates involving an adverb (run out) or a co-predicative participle (go out running, sortir en courant). They all refer to the circumstances of an action or to coincident actions and constitute one single event, in contrast with multiclause constructions which refer to sequential events such as $i$ thege me $i$ ulep $d u$ 'he runs and goes out', il sort et (il) court.

There are many common points between asymmetrical serial verbs, medial verbs and converbs (König 1995; Haspelmath 1995: 5, 23-27, 3745; Bisang 1995: 137-88), they specify the circumstances of the main action (manner, intrumental, concomitance, locative, etc.), with a similar scale of desententialization (Lehmann 1988: 200). But there is a major difference: asymmetrical serial verbs may only be modifiers of verbs and do not display any dependency marker or nonfinite verb morphology, while converbs are nonfinite verb forms [such as adverbial participles they eat laughing or periphrastic converbs such as French il l'a fait en chantant] whose main function is to mark adverbial subordination, they are modifiers of verbs, clauses or sentences (Haspelmath 1995: 3, 6-9, 12-17). Besides, serial verbs and converbs alike may specialize and grammaticalize into adpositional or case-role markers (or "coverbs" Li \& Thompson 1974a), applicative markers or conjunctions (Haspelmath 1995: 37-42).

\section{Structural compression}

Languages show various degrees between two poles: towards more syndesis or more desententialization (Lehmann 1988: 210-13). Formal compression often correlates with economy of form, discourse, pragmatic functions and semantic proximity, as much as with syntactic binding.

Croft (2001: 352-53) suggests that the pathways from less to more tightly integrated linkage and clause fusion are oriented from syndetic to asyndetic coordination, on to co-ranking serialization, leading some verbs to specialize and grammaticalize as governing verbs in complement 
constructions or as subordinating functors or conjunctions in subordinate constructions.

\subsection{Tightening linkage and structural integration or compression}

The sole nuclear type exhibited by most of the languages in this volume might result from the reduction of the same-subject or different-subject core types, through gapping, ellipsis and argument fusion ${ }^{20}$. This would result in one single nuclear juncture with two different structural subtypes encoding different syntactic relations: (i) symmetrical/co-ranking nuclei referring to sequential actions and (ii) asymmetrical modifying nuclei displaying argument fusion and possibly transitive or number concord. Polyfunctionality would thus arise, as often, from gradually merging structures, with an intermediate period in which both types co-exist, one becoming dominant and the other receding.

The centripetal tendencies towards integration and compression occur at all levels, from sentence and clause level to core and more desententialised nuclear juncture and further down on the scale of desententialization, favoured by contiguity (Lehmann 1988), at word level toward lexicalization, compounding, grammaticalization or morphologization.

7.2. Tightness of linkage and semantic or pragmatic integration

Languages make different choices as to which functions (modification or sequential actions) are thus compressed (see 6.2.1 above). Tightness of linkage often correlates with semantic closeness and is subject to the same subject constraint and topic continuity. In Anejorm, clauses with samesubjects allow some free choice between the four types of clause-linking: (i) asyndetic (parataxis), (ii) syndetic (conjunctive) clause-linking, (ii) "echo-subject" clause-chaining or (iv) infrequent nuclear serial ${ }^{21}$ constructions, whereas different subjects or different aspect-mood operators bar nuclear serialization, favouring parataxis or conjunctive aspect-markers (Section 2).

This highlights some cross-linguistic tendencies of syntactic, semantic and pragmatic integration such as those analysed by Givón (1980) in his extensive research on English complementation and on the covariation between tight linkage, the semantics of the governing verb (desiderative, manipulative, perceptive, etc.) and contextual semantics. For instance, the 
type of complementation ( $\varnothing$, to, that, -ing) is sensitive to aspectual semantics, as in I remembered taking the portrait (process) vs I remembered to take the portrait (action), or he began to dance (onset of action) vs he began dancing (initial phase of the process).

The degree of integration thus covaries with the type of conceptual relations that languages conflate or distinguish. Some cross-linguistic features are however apparent. Foley \& Van Valin (1984: chap. 6) have proposed a hierarchy of the correlation between tightness of linkage and semantic integration, which is only partly verified in this volume. They propose the following cline of semantic and functional domains, ordered from tight linkage (single event) to weak linkage (distinct events):

causative $>$ aspectual $>$ psych action $>$ purposive $>$ jussive $>$ perception $>$ propositional attitude (love, hate) $>$ cognition $>$ indirect discourse

$>$ temporal adverbial $>$ conditionals $>$ simultaneous actions $>$ sequential actions (+/-overlapping) > action-action (unspecified)

Tight nuclear juncture or looser core juncture in the languages of the volume (in bold italics) mostly concern adverbial modification (manner $>$ circumstances), aspectual, time (simultaneous actions $>$ sequential actions), purposive, causative, and resultative. Another common feature of serial constructions is their high polysemy, they encode sequential actions, actionpurpose, cause-effect and cause-result, which constitute a semantic continuum with no clear-cut boundary between them.

Thus, Mwotlap's "macro-verbs" have a variety of closely related semantics (causative, purposive, resultative, depictive, manner of action) filtered by context. Samoan's juxtaposed constructions (Mosel) also have a variety of context-dependent meanings: [ex. 24] lamu fa' $a$-malü (lit. chew CAUS-soft) may be interpreted as purposive 'chew to soften' or as expressing manner of action 'soften by chewing', [ex. 25] tapena fa'a-lelei le fale (lit. tidy up CAUS-good the house) 'tidy up the house so that it looks good' expresses purpose and cause-effect. A similar semantic continuum is apparent in the English conjunction 'so that' which may have consecutive, resultative or purposive reading depending on the sentence's TAM information. Compare: he works hard so that he'll get the job (to get the job, purpose) and he worked hard so that he got the job (and he got the job, result). 


\subsubsection{Integration of action-purpose goal}

The choice of a tight serial construction vs syndetic subordination for purposives is cross-linguistically common (Croft 2001: 352) and shows a tendency to compression whenever semantically allowed. The main difference is structural (one vs two clauses) and conceptual (one vs distinct events).

\section{Syndesis $v s$ serial constructions}

In Nêlêmwa, Tahitian and East Uvean, purposives can either be expressed by contiguous nuclei or as distinct events by a subordinate construction marked by a polyfunctional conjunction: in Nêlêmwa me (marking sequential coordination, action-goal dependency and complementation), in Tahitian no (marking subordination and complementation), in East Uvean mo (for coordination, additive properties, concomitant actions) or $o$ ('and/to' for coordination, purposive). In East Uvean, Moyse-Faurie shows that some contiguous nuclei [ex. 57, 58] with sequential or purposive meaning involving a few verbs of motion or stance (go, come, stand) might result from conjunction ellipsis of $o$ 'and/to'.

- Types of serial constructions

ZSequential actions and action-goal (such as 'he came and told me / he came to tell me') are often expressed by serial constructions: by core serialization Iin Saliba (Margetts, 6.2.) or by contiguous nuclei (Teop, Nêlêmwa, Pileni, East Uvean). In Mwotlap, Samoan and Tahitian only purpose or goal (but not sequential actions) is marked by contiguous nuclei. For an illustration of this in Mwotlap, see François [ex. 27] gengen maymay (lit. eat strong) 'eat well to strengthen your body'; [ex. 48] ōl tog-yoñ magaysēn (lit. callstay quiet-sad) 'we call (devil) to scare the kids silent'.

\subsubsection{Integration of cause-effect and resultative constructions}

Cause-effect and resultative meanings are also frequently expressed by serial constructions across languages. They are tightly related concepts in that they constitute the boundaries of an event or action, either its origin/cause or its endpoint/result. In Nêlêmwa (Bril), these constructions also express the endpoint or goal of motion: [ex. 20] i caabwa-da kuut (lit. he get up stand) 'he gets up to his feet'. In Mwotlap (François), contiguous 
nuclei may also express the temporal endpoint of the action: [ex. 21, 22] hag $q \bar{o} \bar{n}$ (lit. sit be night) 'stay until night/stay all day' or lak meyen (lit. dance be day) 'dance until day / dance all night'.

\subsubsection{Causality ${ }^{22}$ and causative constructions}

In the languages of this volume, causative constructions are dominantly expressed either by causative affixes (Nêlêmwa) or by complex clauses. In Mwotlap, with the decay of the causative affix (François 3.2, fn. 13), causative constructions are expressed by complex verbs expressing action cause $\left(\mathrm{v}_{1}\right)-\operatorname{result}\left(\mathrm{v}_{2}\right)$, in which $\mathrm{V}_{1}$ behaves as a "light" causative operator as in [ex. 23] (lit. sun shine melt ice), 'the sun melts the ice'.

English shows similar constructions in which the first verb behaves as a light causative verb and the second one is a nonfinite secondary verb ${ }^{23}$; they may tighten into contiguous nuclei as in he let the blanket fall vs he let fall the blanket, he made two dancing images appear vs he made appear two dancing images. Such contiguous nuclei are licensed either by the AUX-V pattern of English, as in let fall where let behaves as a semiauxiliary, or by the head-adjunct pattern, as in pulled open in which open functions as an adverbial predicate, very much as in Mwotlap. Complex verbs are thus an intermediate stage between the highly integrated morphological expression of causation, semi-grammaticalized causative operators and multiclausal constructions.

\subsubsection{Cause-effect and resultative constructions}

Notions of cause, means of action and result are closely related as in he hammered it soft. In Saliba (Margetts) [ex. 4] sikwa-he-beku-dobi (lit. poke-CAUS-fall-go.down) shows the same semantic ambiguity, '(he) poked making it fall' or '(he) made it fall by poking it', so does Mwotlap (François), see [ex. 9b] tit teñteñ (lit. punch cry) 'he made (him) cry by punching him'.

Cross-linguistically, resultative constructions may thus be expressed by contiguous nuclei as in Teop (Reinig) [ex. 48] tasu va-mate e kahi (lit. stone ADV-be.dead the dog) 'stone the dog to death', or by discontinuous complex predicates ${ }^{24}$ as in English he struck him dead, in which there is no internal role assignment by the adjectival predicate dead.

Some languages distinguish direct result expressed by complex verbs and looser cause-result relations expressed by conjoined clauses (Lord 1975: 28). They are often marked by switch-subject core-layer construc- 
tions [SVO (S)V] with the possible evolution of $\mathrm{V}_{2}$ as a non-autonomous resultative marker. In Numbami (Austronesian, Huon Gulf family, Papua New Guinea, Bradshaw 1993: 138) for instance, former cause-result serial verb constructions have evolved into non-autonomous resultative predicates which must be used in conjunction with verbs. To a limited extent, English shows similar constructions which may tighten into contiguous nuclei [SVOV > SVVO]: he pulled the flap open vs he pulled open the flap.

\subsection{Secondary predication and serialization: some comparisons}

Larson (1991) pointed out strong similarities between "secondary predication" or adverbial "small clauses" in non-serializing languages and core or nuclear serial constructions, in terms of structural compression, polyfunctionality and polysemy.

Various languages in this volume use contiguous nuclei with adjunct functions and meanings which are similar to English adjectival complements such as loom large, fall silent, plead innocent, run wild, spring open or similar to "secondary predication" in English. In English, "secondary predication" involves non-contiguous nuclei, the second one belongs to a closed set of adjectival predicates and mostly specifies the circumstances or Zmanner of action with several possible readings: (i) resultative as in, he worried himself sick, she drank it empty, she beat him silly, he licked the plate clean; (ii) depictive as in she was born blind, they burnt her alive, he came home drunk, they married young, the sun shone bright; (iii) purposive as in kiss it better. The resultative and purposive types are delimiting, whereas the depictive type, which qualifies the subject or the manner of action (he scared the children stiff), is non-delimiting (Larson 1991: 201). Compare in this volume: Mwotlap [ex. 35] bōw liwo (lit. bring up big) 'bring up till one is big', [ex. 36] vatne lolmeyen (lit. teach wise) 'teach to make wise', with Teop [ex. 40] hio tamaka (lit. sit be sad) 'she sits mourning', Nêlêmwa [ex. 21] not kuut 'watch standing', East Uvean [ex. 13] 'alu tagi 'arrive crying', Samoan [ex. 46] 'ai ola 'eat live', [ex. 47] lele tauaso 'fly blind', [ex. 50] tupu maualuga (lit. grow high). Samoan's depictive constructions can also be rephrased as adverbial clauses, as in [ex. 49] fänau mai 'o tauaso (lit. born blind) in which the short form of the progressive marker 'o marks the clause as subordinate. 


\subsection{Ellipsis vs structural compression}

Can monoclausal serial constructions be derived from underlying multiclauses?

Foley and Olson (1985: 19-22) argue against this on semantic grounds, showing that, in various languages, ${ }^{25}$ serial constructions and two-clause constructions have different meanings. However, obligatory and optional serial constructions should be distinguished. The obligatory type is structural and correlates with the conceptualization of events (one event $v s$ several events), it does not entail any loss of informative structure, and circumscribes semantic ambiguity within tolerable limits within a contiguous semantic domain. Adverbial nuclear serialization cannot be analysed in terms of ellipsis. By contrast, optional serialization resulting from conjunction ellipsis and pronoun gapping is tolerated as long as syntactic and semantic interpretation is not impaired, otherwise multiclausal strategies involving conjunctive or dependency markers are resorted to (see Mwotlap, Nêlêmwa, Tahitian, East Uvean).

The syntactic constraints and limits imposed on nuclear serial verbs vary across languages; almost universally, different TAM markers will trigger multiclausal constructions, whereas the same subject constraint is very variable. In Mwotlap, a macro-verb has only one subject and object, but while the subject of each component of the macro-verb may be similar or different, its object must be similar (François, 2.2; [L]): if the macro-verb comprises two transitive nuclei with a different object, one of them is left unmentioned if already referential, or a two-clause construction is required.

\section{An overview of some evolutionary tendencies}

Compression and integration are cyclic processes which may affect several levels: (i) clause level (with loose or tight linkage and binding), (ii) lexical level and word form (compounding and boundness), or (iii) morphosyntactic level (cliticization and morphologization). Once a certain degree of compression and erosion is reached, it may in turn trigger lexical refection to make up for lost morphology (Vinogradov 1987) or the recourse to multiclausal constructions rather than contiguous nuclei. Generally, symmetrical contiguous nuclei are known to develop into co-lexicalized compounds whereas asymmetrical nuclei tend to grammaticalize. This is evidenced in the languages of this volume. 


\subsection{Idiomaticization, lexicalization and lexical compounding}

Contiguous nuclei are commonly the source of idiomatic, co-lexicalized compounds which create new lexical entries and trigger categorial change.

"[...] the degree of morphological compactness [...] reflects the degree of conventionalization of the ideas as a single unit." (Bruce 1988: 22).

Most languages in this volume show such ongoing evolution (Anejo $\widetilde{m}$, Mwotlap, Nêlêmwa, New Caledonian languages, East Uvean), with various degrees of semantic predictability and transparency, functional restriction and autonomy. There are numerous such cases in Mwotlap: consider [ex. 58, 4.2] tot gal (lit. chop tell lies) 'sculpt, carve an image, portray'. François refrains from labelling them lexical compounds on two main criteria: morphophonological (they are distinct phonological words) and syntactic separability.

Senft (this vol.) also mentions several such examples in Papuan languages ${ }^{26}$; in Kalam and Tairora, Pawley (1993) describes serial verbs as an intermediate configuration between one and multiclausal structures, involving co-lexicalization (the most frequent option) or less frequently cogrammaticalization as tense-aspect markers. Manam (Lichtenberk 1983) is another such case of a language with no serial verbs but productive verb - compounding, so are some New Caledonian languages (Ozanne-Rivierre \& Rivierre, this vol.).

In Anejo $\widetilde{m}$ (Lynch, Section 6) the scarcity of serial verbs also correlates Wwith the proliferation of 'deserialized' verb compounds which constitute one single stress unit in which the second item has preserved most of its modifying functions.

8.2. A cline from specialization to grammaticalization, morphologization and phonological erosion

Apart from co-lexicalization, adjacency in the nuclear type provides a strong potential for specialization and co-grammaticalization in one of two possible directions, centripetal (as a verbal adjunct or transitive marker) or centrifugal (as an adposition marker) (see Rivierre, this vol.). 


\subsubsection{Functional specialization of verbs}

Functional specialization is an intermediate stage between lexical and grammatical categories or functions, varying with context and position. Yet, synchronically, both specialized and non-specialized functions coexist.

In Nêlêmwa (Bril, 2.9.1), some verbs may have a slightly different meaning in $\mathrm{V}_{2}$ position: $\hat{a}$ 'go, leave' > 'from place to place', wâlem 'walk' $>$ 'quick(ly)', bwage 'return' > reversive meaning 'back'. In Mwotlap, various verbs also evolve into weak or strong causative verbs ('help', 'blow', etc.); Mwotlap also displays a verb veteg 'leave' [ex. 64] now mostly used to indicate the standard of comparison. It is the only example of such a function in this volume.

Various Aktionsart verbs ('start, begin, last') and modality verbs ('hope, expect, be quiet') are intermediate categories, between full verbs and aspect or modal operators (see Mwotlap, Nêlêmwa, Pileni, East Uvean) and their syntactic function and status is difficult to assess (see 6.2.3 above). In East Uvean [ex. 35b] the verb 'amanaki 'hope' specializes as an aspect marker meaning 'be about to'.

Categorial indeterminacy is often increased by the fact that, though they have undergone specialization, many entities preserve some residual verbal properties. Thus, deverbal adverbial adjuncts may preserve their transitive suffix in complex verb constructions (Nêlêmwa). In various languages (Mwotlap, Nêlêmwa, East Uvean), there are no clear-cut frontiers but a graded continuum between lexical units, functionally specialized entities and grammaticalized entities. This is enhanced in many Polynesian languages, particularly Samoan and Tahitian (this vol.), for words are not categorized prior to their syntactic constructions and environment and there is little or no distinctive finite vs nonfinite verbal morphology. Consequently, contiguous nuclei involve much categorial and functional indeterminacy, and their syntactic and semantic interpretation is context and position dependent.

\subsubsection{Grammaticalization and morphologization}

Specialization may in turn lead to grammaticalization, sometimes entailing categorial change, modified semantic features, reduced or increased semantic field, development of more abstract conceptual and logical relations and meanings. It may also entail the reduction of inflectional 
morphology and loss of phonological form; such processes are ongoing in Anejom and in some New Caledonian languages, especially in southern languages (Ozanne-Rivierre \& Rivierre this vol.) and in some Vanuatu languages; thus in Lewo (Epi Island, North and Central Vanuatu subgroup, Early 1993: 65-67), the nuclear type shows an advanced degree of incorporation, "most serialized verbs have become indistinguishable from a class of verb affixes and move towards verb incorporation"; a similar development is at work in Paamese (Crowley 1987: 82); whereas this process is much less advanced in Mwotlap.

Considered in a typology of diachronic evolution, the phenomena explored by Ozanne-Rivierre and Rivierre in various New Caledonian languages illustrate the tendency that leads from isolation (serial verbs) to boundness and fusion. Paicî has developed proliferating compounds in which the first element is phonologically reduced. These compounds display a high degree of morphophonological attrition, morphologization and fusion; they may even integrate a cliticized subordination marker such as ${ }^{m} b \bar{a} n \bar{\Lambda}$ 'so that, in order to' in a compound, as in [ex. 26] $t \bar{u}-m b \bar{a}-t \bar{u} u$ 'make fall, let fall from one's hands' (lit. put one's hand so that fall). The whole compound adopts the tone of the prefix.

As Bisang (1996: 523-524) shows, grammaticalization is sensitive to "attractor positions", i.e. "catalyzer" slots in which linguistic items are Zattracted and grammaticalized. In the languages of this volume, four slots Zare dominant: direction/orientation, TAM, adjunct and adposition slots. They also coincide with the most common historical paths of development zof serial verbs.

a. Various verbs tend to grammaticalize into adpositional or applicative markers, TAM markers, conjunctive verbs or conjunctions:

(i) Cross-linguistically ${ }^{27}$, the most common verbs which grammaticalize as adpositional or applicative markers are 'give' ( $>$ benefactive), 'surpass' ( $>$ comparative), 'use' ( $>$ instrumental), 'come' ( $>$ ablative), 'go' (> allative), 'be at (> locative), 'take' (> comitative, instrumental, patient marker, see below).

In Oceanic languages, Durie (1983) and Ross (this vol.) analyse the evolution of various serial verbs into adpositional coverbs or adpositions marking peripheral participants and case-roles, especially Proto Oceanic *pani 'give' $>$ dative (benefactive), *su(ldR)i 'follow' $>$ prolative 'about'.

Thus, in Nêlêmwa, [ex. 50] oxuri 'follow' specializes with the meanings 'along', 'according to'. 
(ii) In Oceanic languages, grammaticalization as TAM markers essentially concerns deictic verbs of direction ('go','come'), posture verbs ('sit', 'stand') or Aktionsart verbs ('begin','finish'). In East Uvean [ex. 36b], lolotoga 'to last' has almost fully grammaticalized as a progressive aspect marker.

(iii) In Oceanic languages, the main source of directional or deictic morphemes are grammaticalized directional or motion verbs.

Ross (this vol.) shows that the Proto Oceanic verbs 'go' and 'come' have mostly grammaticalized as post-verbal clitics in $\mathrm{V}_{2}$ position in Oceanic languages, (see Anejo $\widetilde{m}$ Lynch, 7.2, this vol.). Their grammaticalization as preverbal clitics is much less common and stems from Proto Oceanic verb sequences such as 'go/come and...'; Teop (Reinig, 4.3) shows such an evolution.

(iv) Ozanne-Rivierre and Rivierre (this vol.) analyse the gradual development of contiguous verbs involving gesture and action into compounds with a $\mathrm{V}_{1}$ shortened into a prefix and expressing manner of action. Lynch (Section 6) analyses similar cases in Anejom.

(v) The grammaticalization of serial verbs into conjunctive verbs or conjunctions is analysed in 8.2.3 below.

The verb 'take' shows various degrees of grammaticalization in several languages (this vol.). In Pileni (Naess, 4.3), in core serialization, 'take' as $\mathrm{V}_{1}$ has two functions: it gives prominence to a patient or specializes as an incipient or volitional marker; the difference lies in the position of the patient: between the verbs in the former $\left[\mathrm{sV}_{1} \mathrm{O} \mathrm{sV}_{2}\right]$ or after both verbs in the latter $\left[\mathrm{sV}_{1} \mathrm{sV}_{2} \mathrm{O}\right]$. The latter evolution offers an interesting parallel with the use of 'take' in English to mean 'start a new habit' (he took to drinking).

Ozanne-Rivierre (this vol.) analyses the various types of grammaticalization and morphologization of 'take' in several northern New Caledonian languages, either (i) as a compound, with a strong tendency to fusion into one single transitive verb (as in Nemi tuut fe 'stand take') > tüe 'adopt (a child)', (ii) as an enclitic transitivizer in causative constructions (Nyelâyu pha 'take' > -va: pa-wec-va (CAUS-be born-TRANS) 'bring into the world') or (iii) as an enclitic associative case-marker ${ }^{28}$ (Nêlêmwa fhe 'take' > -ve (+inanimate), -vi (+animate): $m u$-ve 'stay with').

In Mwotlap, it is the verb tey 'hold' which grammaticalizes as a comitative case-role marker in [ex. 47] 'dance with me', as an associative case-role marker [ex. 60] 'dance with my shoes on' or to mark an even 
more abstract relation as in [ex. 61] 'slow with their work'. In contrast with the one-stage process 'hold', 'take' is a two-stage dynamic process (grab+hold), which might favour its common evolution as as transitiveapplicative marker or as a causative morpheme. But, if there are several instances of argument and valency adding serial constructions, there is no example of valency reduction in this volume.

\subsubsection{From serial verbs to clause binding}

There are intermediate stages in the gradual evolution which leads from co-ranking to asymmetrical and subordinate, governed predicates belonging to different clauses (see Nêlêmwa, Bril, Section 4). Besides, some verbs specialize or grammaticalize as clause-linkers, conjunctive verbs or complementizers (see Nêlêmwa khabwe 'say' > 'that'; uya 'arrive' extends its semantic range from space to time boundary meaning 'until'). Binding and embedding increase as the matrix predicate gains more control and as the other predicate loses autonomy. This explains how former co-ranking Aktionsart or action verbs (lit. he starts he works) gradually become asymmetrical dependent constructions (as in 'he starts working'). In Nêlêmwa, the construction of thaaxa 'begin' is conditioned by the valency of ${ }_{2} \mathrm{~V}_{2}$ : tight nuclear serialization correlates with an intransitive $\mathrm{V}_{2}$ while a two colause construction with the conjunction $m e$ is required with a transitive $V_{2}$. It

(1)

8.3. Cyclic evolutions: from isolation to boundness and fusion and from erosion to refection

The data explored in this volume display various stages of some common evolutionary processes: compression from core to nuclear serialization, degrees of dependency from co-ranking constructions to asymmetrical dependent constructions (implying modification, governance). Saliba evidences such a process of compression; Margetts shows that sequential core serial verbs tend to evolve into the nuclear type by moving the nominal object $(\mathrm{O})$ out of its VP to become the argument of a macro-verb within the basic SOV order; thus $\left[\mathrm{sV}_{\text {intr. }}\right.$ OsVo] order as in [ex. 25, 26] evolve into [(S)O sV $\mathrm{sintr}_{\mathrm{sVo}} \mathrm{s}$ order as in [ex. 29a, 30a, 31a], [ex. 29a] $\mathrm{O}_{\mathrm{Sioni}} \mathrm{sV}_{\mathrm{go}} \mathrm{sV}_{\text {see }} \mathrm{O}$ 'I go and see Sioni'. But such object movement cannot be ascribed to topicalization. 
This volume also explores several evolutionary paths on different levels: degrees of grammaticalization (into operators, case-markers, conjunctions) and morphologization at the morphosyntactic level, and degrees of colexicalization and compounding at word level. At the extreme end of compression and fusion at word and morpheme level, phonological attrition, the decay and loss of bound morphology may occur and trigger the development of rigid word order to compensate for that loss and the refection of grammatical functions by recourse to the lexicon (see Lehmann 1986, Hagège 1993, to cite but a few). Thus, quoting Foley and Olson (1985: 51):

"Phonological attrition causes syncope of segments or syllables, with the result that phonemic tone or complex vowel systems develop to compensate for phonemic distinctions being lost.". [When] "valence-marking verbal morphology is lost, a new device for valence adjustment must be found. Verb serialization begins to be used in this function, provided serial constructions already exist in the language. Thus, no new pattern is being created. Rather, the function of an already existing pattern is simply extended. $[\ldots]$ the use of serial constructions to indicate valence increases is a function of the isolating structure of these languages."

The great structural variety of serial and complex verbs in this volume and more generally in Oceanic languages could be seen as the synchronic manifestation of various phases and stages of this evolutionary process. This might also apply cross-linguistically and might account for the considerable similarities of functions and meanings of complex verb constructions across languages, in spite of the great variety of structural patterns and language-specific parameters and syntactic constraints. 
Oceanic languages cited and language sources.

(Italicized names refer to subgroups or linkages)

- Western Oceanic:

- North New Guinea

- Manam (Manam and Boesa Islands, Papua New Guinea; Lichtenberk 1983).

- North Huon Gulf: Jabêm (Bradshaw 1983, Bisang 1986, 1995); South Huon Gulf: Numbami (Bradshaw 1993).

- Papuan Tip

- Kilivila (Trobriand Island, Senft 1986, 1987); Saliba (Saliba Island, Milne Bay province of Papua New Guinea, Margetts 1999).

- Meso Melanesian

- South New Ireland subgroup: Tolai (East New Britain, Papua New Guinea; Mosel 1984).

- North-West Solomonic linkage

- Teop (North Bougainville, Mosel 1999, Reinig 2000).

- Eastern Oceanic:

- Southeast Solomonic

- Toqabaqita (Malaita Island, Solomon Islands; Lichtenberk 2000).

- Remote Oceanic

- Southern Oceanic subgroup

- North-Central Vanuatu: Mwotlap (François 2001), Paamese (Crowley 1987), Araki (François 2002), Lewo (Early 1993), Namakir (Sperlich 1993).

- South Vanuatu: Anejō̃ (Lynch 2000), Lenakel (Lynch 1983), Sye (Erromango Island, Crowley 1998).

- New Caledonian: Far North of Mainland: Nêlêmwa (Bril 2000, 2002), Nyelâyu (Ozanne-Rivierre 1999); North of Mainland: Cèmuhî (Rivierre 1986), Nemi (Ozanne-Rivierre 1979), Paicî (Rivierre 1983); South of Mainland: Ajië (Leenhardt 1932, La Fontinelle 1976, Aramiou et al. 2001), Xârâcùù (Moyse-Faurie 1995).

- Central Pacific

- Nuclear Polynesian: East Uvean (Moyse-Faurie, to appear).

- Proto Ellicean: Samoan (Mosel and Hovdhaugen 1992);

- Ellicean Outlier Pileni (Solomon Islands, Outlier Polynesian language; Næss 2000, Hovdhaugen et al. 2002).

- Eastern Polynesian: Tahitian (Fortunel 1993, Lazard and Peltzer 2000). 


\section{Notes}

1. I am grateful to Alexandre François, Françoise Ozanne-Rivierre and Malcolm Ross for their insightful comments on an earlier version of this article.

2. Or non-existent as in Manam (North New Guinea subgroup of the Western Oceanic branch, Lichtenberk 1983).

3. As in some African and Creole languages.

4. An event is defined as "a basic unit of thought or conceptualization [...] including causation, inception, state, deixis, termination" and "a complex event as two or more units of thought or conceptualizations" (Bodomo 1997).

5. "Scope" is defined as the syntactic domain of a semantic operator (Byrne 1991:210).

6. Transitive concord is attested in various Oceanic languages, among which North and Central Vanuatu languages: Lewo (Epi Island, Early 1993) and Paamese (Crowley 1987).

7. A neighbouring language. François (2002) calls such constructions "clausechaining".

8. In Igbo (Kwa family, Lord 1975: 25-26), nuclear serialization is not attested with stative and intransitive verbs (cited in Foley and Olson 1985: 42).

9. The basic order is mixed: SOV with nominal arguments and sVo with pronouns. There are other mixed ordering features: GEN-N; DEM-N; but N-ADJ; N-NUMERAL; V-ADV.

10. Universal 13: "If the nominal object always precedes the verb, then verb forms subordinate to the main verb also precede it. SOV $>\mathrm{S} \mathrm{O} \mathrm{V}_{\text {sub. }} \mathrm{V}_{\text {main }}$ (Greenberg 1966:11).

Universal 15: "In expressions of volition and purpose, a subordinate verb form always follows the main verb [...] except in those languages in which the nominal object always precedes the verb."

11. Agent $>$ instrument $>$ patient $>$ goal $>$ locative $>$ comitative $>$ beneficiary, etc.

12. "To deal with this, we would need a theory of lexical semantics that will allow integration of the conceptual structures of such verbs to produce a single fused set of theta-roles for the combined predicate. Such a theory would offer a framework for a unified semantic treatment of the argument sharing properties of both contiguous and non-contiguous serialization." (Durie 1997: 303-304).

13. Though this is not recognized as a possible function of serialization in Baker's approach, as pointed out by Durie (1997: 308):

"Baker's model demands that the overall argument structure of a serial chain be no more complex than that of the final verb in the chain".

14. Or fetch expressed as 'go take come back', or bring expressed as 'hold come', or tell expressed as 'speak give', or kill as 'hit die/be dead'.

15. Formulas are "systems of knowledge that bind together pragmatic knowledge (of a world and discourse about that world) with semantic, syntactic and 
idiomatic-stylistic knowledge, and in which the pragmatic and semantic elements are primary." (Pawley 1993: 116).

16. There are only about a hundred verbal items in Kalam (Pawley 1993: 96).

17. "We speak of pseudo-complementation when we have to do with a clausal or sentential structure [...] which is treated syntactically as if it were a normal Scomplement, whereas its semantic role is not that of an S-complement but, rather, one of concomitant, resultative or purposive circumstance or event. A pseudo-complement is a suppositious sentential complement foisted on the syntax of a verb which either does not require such a complement semantically, or, if it does, does not allow for it on grounds of lexico-grammatical restrictions. [..] Verb serialization is typically ungoverned pseudocomplementation." (Seuren 1991: 196-97).

18. "If the (selectional) restrictions reside in the superordinate governing verb and the content of the pseudo-complementation is lexically unrestricted, [...] we are not facing [...] verb serialization. (Seuren 1991: 203).

19. In Korafe (Papuan, Farr 1993), serialized verbs and clause-chaining coexist on a cline from tight to loose binding.

20. Core $[\mathrm{sV}(\mathrm{o}) \mathbf{s V}(\mathrm{o})]>$ nuclear $[\mathrm{sVV}(\mathrm{o})]$.

21. Mostly restricted to verbs of direction.

22. Causality encompasses both origin and causation.

23. Causative constructions such as I made him do it are also analysed as "predicate composition" rather than complementation (Andrews 1997: 9).

24. As in Sranan (Creole of Surinam) Kofi naki Amba kiri (lit. Kofi hit Amba kill) 'Kofi killed Amba', which Baker (1989: 524) analyses as a case of object乙 sharing.

25. Kwa languages of West Africa (Yoruba, Anyi - Ivory Coast), Lahu (TibetoBurman) and Yimas (Papuan language, Sepik region, Papua New-Guinea).

26. For Alamblak, see Bruce 1988.

27. See Foley and Olson (1985: 48); Seuren (1991: 203). For Oceanic languages: Pawley 1973, Lichtenberk 1985, Hamel 1993. For Asian languages: Li \& Thompson 1974a, Hagège 1975, Clark M. 1978, Peyraube 1988, Bisang (1995: 534, 570). For West African languages: Ansre 1966, Lord 1973, 1993, Givón 1975, Heine \& Reh 1984.

28. 'Take' may also grammaticalize as an applicative-transitive marker with instrumental case-role, as in Dagaare (North Ghana; Bodomo 1997). 